\title{
ESPAÑA Y EL ARTÍCULO 3 DEL CONVENIO EUROPEO DE DERECHOS HUMANOS: UN BALANCE ${ }^{1}$
}

\author{
IGNACIO ÁLVAREZ RODRÍGUEZ \\ Profesor Ayudante-Doctor de Derecho Constitucional \\ Universidad Complutense de Madrid
}

\begin{abstract}
SUMARIO
I. A modo de introducción. II. El artículo $3 \mathrm{CEDH}$ en general: la protección de un valor absoluto e inderogable. III. El artículo $3 \mathrm{CEDH}$ en particular: las condenas a España. IV. La reacción de España ante las condenas. V. A modo de conclusión.
\end{abstract}

\section{A MODO DE INTRODUCCIÓN}

En el presente texto se ofrece un análisis sobre las condenas a España por vulnerar el artículo $3 \mathrm{CEDH}$. Para ello se hace en primer lugar una sucinta exégesis del precepto, resaltando la importancia que para el sistema del Convenio tiene ese valor - la prohibición de la tortura- así como las dos vertientes que lo integran, la sustantiva y la procesal. Después se aborda el caso concreto de nuestro país, analizando los principales motivos de condena ${ }^{2}$. A continuación, se sistematiza la reacción de España frente a tales condenas, haciendo especial hincapié en la integración de los criterios de Estrasburgo por parte de nuestro Juez Constitucional, así como en ciertas reformas legislativas implementadas. Finalmente se aportan algunas reflexiones a modo de conclusión.

\section{EL ARTÍCULO 3 CEDH EN GENERAL: LA PROTECCIÓN DE UN VALOR ABSOLUTO E INDEROGABLE}

Es bien sabido que el artículo 3 CEDH establece que: «Nadie podrá ser sometido a tortura ni a penas o tratos inhumanos o degradantes» ${ }^{3}$. El TEDH ha reiterado que este

1 Este trabajo se realiza en el marco del Proyecto de Investigación DER2016-75993, sobre España ante Europa: retos nacionales en materia de derechos humanos (2016-2020).

2 Una visión de conjunto puede verse en el trabajo de Matia Portilla, F.J; «Examen de las sentencias del Tribunal de Estrasburgo que afectan al Reino de España», publicado en este mismo número.

3 Vid. Salado Osuna, A; «Los tratos prohibidos en el artículo 3 del CEDH». En García Roca, J; y Santolaya Machetti, P; (coords); La Europa de los Derechos. El Convenio Europeo de Derechos Humanos, CEPC, Madrid, 
precepto recoge uno de los valores fundamentales de toda sociedad democrática, goza de carácter absoluto («no permite excepciones, matizaciones, o puesta en equilibrio con otros valores» ${ }^{4}$ ), y es inderogable (ya sea en supuestos de normalidad democrática, de contextos de lucha contra el terrorismo, ya sea en cualquier tipo de estado de excepción ${ }^{6}$; ya sea en esos supuestos algo vaporosos conocidos con el nombre de estados/Derecho de emergencia $)^{7}$.

La jurisprudencia del TEDH en la materia, muy abundante, es uno de los activos más sólidos de las democracias europeas ${ }^{8}$. El precepto ha sido aplicado a multitud de situaciones y lugares, manifestando una vis expansiva digna de mención. Así sucede con todo tipo de detención/traslado/custodia policial, así como a la situación del recluido en cualquier lugar (comisarías, cuarteles, cárceles, centros de internamiento psiquiátricos, centros de internamiento de extranjeros), sea por estancia provisional o decretada en firme ${ }^{9}$. Se aplica, huelga decirlo, a las condiciones de cumplimiento de la pena (incluso,

2014 (3. a ed.), pp. 85-112; Santamaría Arinas, R; y Bolaño Piñeiro, M. ${ }^{a}$.C; «Prohibición de la tortura». En Lasagabaster Herrarte, I (dir.), Convenio Europeo de Derechos Humanos: Comentario Sistemático, Civitas, Madrid, 2015 (3. a edición), pp. 54-95. Respecto a la relación entre España y la jurisprudencia de Estrasburgo puede verse Matia Portilla, F.J; «Informe sobre España», en Matia Portilla, F.J; y Álvarez Rodríguez, I (dirs.); Informes nacionales sobre la actuación del Tribunal Europeo de Derechos Humanos, Tirant lo Blanch, Valencia, 2018, pp. 37-70; y Díaz Crego, M. ${ }^{a}$; «La jurisprudencia del Tribunal Europeo de derechos humanos en torno a España: una historia de acuerdos y desencuentros»; En García Roca, J; y Santolaya Machetti, P; (coords); La Europa de los Derechos. El Convenio Europeo de Derechos Humanos, CEPC, Madrid, 2014 (3. a ed.), pp. 791-831.

4 Por todas, ver STEDH Gäfgen c. Alemania, de 1/6/2010, \$107. Sobre el particular vid. Cano Palomares, M.A; En los límites de la exclusión de la responsabilidad penal: el caso de «Jakob Von Metzler» y el empleo de la tortura en el Estado de Derecho, Bosch, Barcelona, 2017; RoIg Torres, M; «Revisión del delito de tortura tras la reciente STEDH de 7 de Octubre de 2014 de condena a España. El debate sobre la «tortura de rescate» (rettungsfolter); Revista de Derecho Penal y Criminología, n. ${ }^{\circ} 11,2014$, pp. 295-364; y Gutiérrez Gutiérrez, I; «La dignidad quebrada»; Teoría y Realidad Constitucional, n. ${ }^{\circ} 14,2004$, pp. 331-343.

5 Vid. López Guerra, L; «El diálogo entre el Tribunal Europeo de derechos humanos y los tribunales españoles. Coincidencias y divergencias». Teoría y Realidad Constitucional n. ${ }^{\circ} 32$, 2013, p. 149. Respecto a la jurisprudencia de Estrasburgo deben destacarse por pioneras la STEDH Irlanda c. Reino Unido, de 18/1/1978; y la STEDH Tyrer c. Reino Unido, de 25/4/1978.

6 Vid. Costas Trascasas, M; «Seguridad nacional y derechos humanos en la reciente jurisprudencia del Tribunal Europeo de Derechos Humanos en materia de terrorismo internacional: ¿hacia un nuevo equilibrio?». En Conde Pérez, E; (dir); e Iglesias SÁnchez, S; (coord): Terrorismo y Legalidad Internacional, Dykinson, Madrid, 2012, pp. 195 y ss. Son señeras la STEDH Tomasi c. Italia de 27/8/1992, y la STEDH Askoy c. Turquía, de $18 / 12 / 1996$.

7 Vid. Canosa Usera, R; El derecho a la integridad personal, Lex Nova, Valladolid, 2006, p. 31 y ss.

8 Por dar algunos datos, esta norma se sitúa en cuarta posición respecto al número de condenas. El TEDH sólo ha condenado más veces por la vulneración de otros tres preceptos. Desde 1959 a 2017, lideran el tenebroso ranking de Estados condenados Rusia (con 58 condenas por torturas y 719 condenas por tratos inhumanos/degradantes); Turquía (con 31 condenas por tortura y 316 condenas por tratos inhumanos y degradantes); y Ucrania (con 15 condenas por tortura y 170 por tratos inhumanos y degradantes). El ranking de lo contrario lo encabezan Liechtenstein, San Marino, Noruega y Portugal, con cero condenas. Las referencias provienen de Echr; Overview 1959-2017, marzo de 2018 (en línea: https://www.echr.coe.int/.../Overview_19592016_ENG.pdf, consultado el 15 de junio de 2018).

9 Por ejemplo, mantener a los reclusos en celdas de diecisiete metros cuadrados, sin luz ni agua, ni colchones y con insectos, es contrario al artículo 3 CEDH (STEDH Kalachnikov c. Rusia, de 15/7/2002; STEDH Karalevicius c. Lituania, de 07/04/2005; y STEDH Kadikis II c. Lituania, 04/05/2006). La privación sensorial absoluta, también conocida como tortura blanca, está prohibida (STEDH Messina II c. Italia, de 28/09/2000). Someter a presos de manera periódica y rutinaria a exploraciones anales atenta contra la dignidad causando angustia y/o humillación, por lo que está prohibido (STEDH Lorsé y otros c. Países Bajos, de 04/02/2003). Más ejemplos: siete meses en una celda donde entraba la lluvia y el sol por un boquete de dimensiones considerables, sin que el recluso apenas saliera al patio exterior (necesitaba silla de ruedas y no se la dieron) está prohibido (STEDH Mathew c. Países Bajos, de 29/09/2005). 
o precisamente, si esta es de muerte ${ }^{10}$. Se aplica cotidianamente a usos de la fuerza por parte de agentes de la autoridad ${ }^{11}$. Se ha aplicado para erradicar prácticas de otro tiempo, como los castigos corporales ${ }^{12}$. La norma rige extraterritorialmente ${ }^{13}$, lo cual exige de los Estados que recaben ciertas garantías de que la persona afectada por la decisión de extradición/expulsión no será sometida a los tratos prohibidos por el artículo $3 \mathrm{CEDH}^{14}$. El precepto ha sido interpretado de forma tan garantista que incluso cae bajo su radio de acción no sólo los actos cometidos por funcionario público sino también los imputables a sujetos privados ${ }^{15}$.

Hechas estas observaciones obligadamente concisas y sucintas, es momento de conocer las dos principales vertientes de la norma.

\subsection{La vertiente sustantiva}

La vertiente sustantiva prohíbe taxativamente que se ejerzan malos tratos, tratos inhumanos, degradantes, y/o torturas. Dicha obligación constituye una obligación sólidamente asentada en el Derecho Internacional de los Derechos Humanos ${ }^{16}$. Tal extremo

También se ha declarado prohibido no dar el tratamiento médico necesario a un preso que lo necesita (STEDH Kudla c. Polonia, de 26/10/2000). Pero la detención y reclusión en una prisión de máxima seguridad no es contrario, en sí misma, al precepto (Lorsé y otros c. Países Bajos, de 04/02/2003), aunque sí lo es atar a un recluso toda la noche a la cama (STEDH Henaf c. Francia, de 27/11/2003).

10 Destacan los casos de aislamiento, donde el TEDH evalúa con mucho cuidado la gravedad de las medidas, su duración, el objetivo perseguido, y los efectos sobre la persona (STEDH Van der Ven c. Países Bajos, de 04/02/2003; y STEDH Renolde c. Francia, de 16/10/2008). De ese modo, un registro semanal donde se mantiene desnudos por tiempo prolongado a los reclusos es contrario al precepto (casos STEDH Van der Ven c. Países Bajos, de 04/02/2003; y STEDH Salah c. Países Bajos, de 06/07/2006); la operación forzosa a un recluso para obtener prueba de culpabilidad también está prohibida (STEDH Jallob c. Alemania, de 11/07/2006). Y el hecho de estar condenado a muerte no empece a que el preso sea tratado con dignidad. Si las medidas y condiciones que existen en el corredor de la muerte no son suficientes a ojos del precepto, el TEDH condena (STEDH Aliev c. Ucrania, de 29/04/2003). Si lo son, no condena (STEDH Ocalan I c. Turquía, de 12/05/2005). Sobre la recepción en el ámbito penitenciario vid. REviRIEGO PICón, F; Los derechos de los reclusos en la jurisprudencia constitucional, Universitas, Madrid, 2008.

11 Un caso relevante es el decidido en la STEDH Cestaro c. Italia, de 7/7/2015, donde la entrada y acción policial por la fuerza en un colegio donde se albergaban algunos manifestantes contra el G-8 en Génova llegó a tal umbral de gravedad que el TEDH lo calificó de tortura (\$190).

12 Nos referimos a esa «violencia institucionalizada» que se ha prohibido desde la STEDH Tyrer c. Reino Unido, de 25/04/1978.

13 En la STEDH Saadic. Italia, de 28/2/2008, se dice que no cabe ponderar, entre otros factores e incluso en el marco de la lucha antiterrorista, la «peligrosidad» del sujeto en cuestión. Vid. Conde PÉrEz, E; «TEDH-Sentencia de 28.02.2008, Saadi c. Italia, 37201/06-artículo 3 CEDH-Prohibición de torturas y penas o tratos inhumanos o degradantes-terrorismo v. tortura», Revista de Derecho Comunitario Europeo, n. ${ }^{\circ} 32,2009$, pp. 275-290.

14 Así, por ejemplo, en la STEDH Chabal c. Reino Unido, de 15/11/1996; en la STEDH Jabari c. Turquía, de 11/7/2000; en la STEDH N. c. Finlandia, de 26/7/2005; en la STEDH Saadic. Italia, de 28/2/2008; y en la STEDH M.S.S c. Bélgica y Grecia, de 21/1/2011. Vid. Casadevall, J; El Convenio..., cit, p. 230 y ss.

15 Por todos, STEDH A. c. Reino Unido, de 23/9/1998, y STEDH Beganovic c. Croacia, de 25/6/2009. Vid. Lavrysen, L; Human rights in a positive state, Intersentia, Cambdrige-Antwerp-Portland, 2016, p. 63; SALAdo OsunA, A; «Los tratos...», cit., pássim. Los Estados deben, pues, adoptar mecanismos legales pertinentes y suficientes, así como medidas razonables para evitar que se materialicen (STEDH Mabmut Kaya c. Turquía, de 28/3/2000. Vid. Casadevall, J; El Convenio..., cit, p. 218.

16 Fernández de CaSAdevante y Romaní, C; «La obligación de investigación efectiva en el Derecho Internacional de los Derechos Humanos: Especial referencia a la práctica española»; Revista Electrónica de Estudios Internacionales, n. $^{\circ} 26,2013$, pp. 1-42; y «El derecho al acceso a la justicia y ana respuesta efectiva en el marco del 
es corroborado por los órganos de supervisión y control de los Tratados Internacionales en la materia, tanto de la ONU (el CDH, el CCT, y el SCT, entre otros ${ }^{17}$ ), como del Consejo de Europa (CPT) ${ }^{18}$.

Desde el punto de vista subjetivo, y sin perjuicio de lo dicho antes, esta obligación es especialmente exigible a todos aquellos que detentan el poder, especialmente a sujetos cualificados tales como los agentes de la autoridad, miembros de cuerpos policiales y similares.

Desde el punto de vista objetivo, el precepto prohíbe tres conductas, que a lo largo y ancho de la jurisprudencia del TEDH son tratadas como derivadas de un nexo común: el atentado contra la dignidad más elemental del ser humano. De hecho, la primera vez que el TEDH habló de dignidad lo hizo precisamente en el marco de un litigio relacionado con este precepto ${ }^{19}$.

sistema regional europeo de protección de derechos humanos», Eguzkilore Cuaderno del Instituto Vasco de Criminología, n. ${ }^{\circ}$ 27, 2013, p. 7-24. Como recuerda la doctrina, estamos ante Derecho Convencional, por lo que su origen está en los tratados y sólo se aplica a quienes los hayan firmado. Vid. DíEz-PiCazo, L.M. ; Sistema de Derechos Fundamentales, Thomson-Reuters-Civitas, Cizur Menor, 2014 (4. ${ }^{a}$ edición), p. 155.

$17 \mathrm{La}$ ONU tiene diversos mecanismos de garantía, como es bien sabido, aunque el que más relevancia ha tenido en los últimos tiempos es el SPT, órgano creado por el OPCAT. Ampliamente inspirado en su hermano del Consejo de Europa, está formado por un grupo de veinticinco expertos que realizan básicamente una labor preventiva, llevando a cabo visitas periódicas a los diferentes centros de detención de los territorios de los Estados miembro (ochenta y siete, a día de hoy). Las visitas finalizan con un Informe que se hace llegar al Estado en cuestión, con las recomendaciones y observaciones pertinentes. Es el Estado quien decide hacerlos públicos o no. Y también es el Estado el que decide si implementa o no las mismas. Para el caso español, la última visita que nos realizó fue en 2017 pero el Gobierno no ha hecho público el Informe. Por lo demás, desde el resto de órganos de protección de Naciones Unidas se nos ha dicho que eliminemos el régimen de detención incomunicada; que se grabe toda actuación en dependencias policiales (grabaciones debidamente custodiadas y a disposición de las partes implicadas); y que se elimine o suavice el régimen de aislamiento en nuestras cárceles así como evitar ciertas prácticas que socavan la credibilidad de estas medidas (por ejemplo: indultar a agentes condenados mediante sentencia judicial por delito de tortura). Desde el CCT puede verse el Informe CAT/C/ ESP/CO/6/2015. ttp://tbinternet.ohchr.org/_layouts/TreatyBodyExternal/countries.aspx?CountryCode=ESP\&Lang=SP (en línea: 2 de junio de 2018); desde la Relatoría Especial de sobre la cuestión de la tortura puede verse el Informe Van Boven, (E/CN.4/2004/56/Add.2, de 6 de febrero de 2004); y desde la Relatoría Especial sobre la promoción y la protección de los derechos humanos y las libertades fundamentales en la lucha contra el terrorismo, el llamado Informe Juan Méndez (A/ HRC/19/61/Add.3 de 1 d marzo de 2012). Vid. Ruiloba Alvariño, J; «Analogías y diferencias entre el sistema europeo para la prevención de la tortura y el sistema instaurado por el protocolo facultativo a la convención contra la tortura de Naciones Unidas», en FERNÁNDEZ SÁNCHEZ, P; La obra jurídica del Consejo de Europa: (en conmemoración del 60 aniversario del Consejo de Europa), Sevilla, Gandulfo, 2010, pp. 263-281.

18 El CPT es el órgano de protección creado por el CEPT, tratado internacional para proteger específicamente el artículo 3 CEDH. Está formado por cuarenta y siete expertos, uno por cada Estado parte y nombrado por este, cuyas funciones se rigen por los principios de cooperación y confidencialidad, implementando un sistema de visitas (periódicas y/o ad hoc) a los diferentes centros de detención de los Estados miembro. Finaliza la misma con un Informe, que sólo el es público si el Estado así lo decide, donde se realiza balance de las luces y sombras de su visita. La iniciativa, en su momento calificada de «revolucionaria», ha tenido las bendiciones doctrinales por su seriedad y rigor. Vid. CAssese, A; «The European Committe for the Prevention of Torture and Inhuman on Degrading Treatment or Punishment (CPT)». En CAssese, A; (ed.); The International Fight Against Torture, Nomos, Baden-Baden, 1991, pássim; Salado Osuna, A; «Las funciones del Comité Europeo para la Prevención de la Tortura», Revista de Instituciones Europeas, 21/2, 1994, p 577; y ss; Morgan, R; y Evans, D; (eds.), Protecting Prisoners. The Standards of the European Committee for the Prevention of Torture in context, Oxford, New York, 1999; y CRUZ, J; El Comité para la Prevención de la Tortura, ENE Ediciones, Valencia, 2001.

19 Vid. Elvira Perales, A; «La dignidad humana en el TEDH». En ChueCa, R; (dir.); Dignidad humana $)$ derecho fundamental, CEPC, Madrid, 2015, pp. 197-234; también puede verse CaNOSA UsERA, R; El derecho..., cit, p. 179 y ss; Oehling de los Reyes, A; La dignidad de la persona, Dykinson, Madrid, 2010; González Pérez, J; La dignidad de la persona, Civitas-Thomson Reuters, Cizur Menor, 2011 (2. a edición); y Gutiérrez Gutiérrez, I; «La dignidad...», cit, p. 333 y ss. La importancia de este valor en la esfera internacional ya fue anotada en su 
Es importante resaltar que la diferencia entre las tres no es una cuestión de principio sino de grado ${ }^{20}$. Así, el TEDH reserva la tortura para los actos de mayor gravedad, basándose en la principal referencia en la materia: el artículo 1 de la Convención contra la Tortura de Naciones Unidas (y específicamente en el hecho de causar graves y severos daños o sufrimientos de toda índole, no tanto en el fin y objetivos perseguidos) ${ }^{21}$. Los tratos inhumanos están en el siguiente escalón, siendo definidos por el TEDH como «aquellos sufrimientos físicos/psíquicos provocados deliberadamente con una intensidad particular» ${ }^{22}$, lo cual incluye indudablemente el maltrato psíquico ${ }^{23}$. Incluso cabe que el TEDH aprecie un mismo acto como trato inhumano y degradante, lo que lo situaría en un estado intermedio ${ }^{24}$. Por último, los tratos degradantes son los de menor intensidad, siendo aquellos «susceptibles de originar temor, angustia, e inferioridad capaz de humillar a una persona» ${ }^{25}$.

Para sentenciar una vulneración material del artículo 3 CEDH, el Tribunal ha ido estableciendo una serie de criterios mínimos que examina a conciencia, bajo la premisa de que superen ese «umbral mínimo de gravedad» ${ }^{26}$, y atendiendo detenidamente a las circunstancias del caso. Así, la casuística que ha llegado a producir este precepto es casi inabarcable y goza de un patrón común: una interpretación evolutiva, expansiva y garan$\operatorname{tista}^{27}$. Con el paso del tiempo el TEDH ha ido estableciendo diversos factores de valoración, tales como la intencionalidad del autor; la duración e intensidad del trato; los

momento por Alzaga Villaamil, Ó; Comentario Sistemático a la Constitución Española, Marcial Pons, Madrid, 2016 (2. ${ }^{a}$ edición), p. 119 y ss.

20 El punto de partida de la delimitación conceptual es la STEDH Irlanda c. Reino Unido, de 18/1/1978.

21 Vid. Salado Osuna, A; «Los tratos...», cit. p. 90 y ss. Artículo 1 de la CT: «1. A los efectos de la presente Convención, se entenderá por el término «tortura» todo acto por el cual se inflija intencionadamente a una persona dolores o sufrimientos graves, ya sean físicos o mentales, con el fin de obtener de ella o de un tercero información o una confesión, de castigarla por un acto que haya cometido, o se sospeche que ha cometido, o de intimidar o coaccionar a esa persona o a otras, o por cualquier razón basada en cualquier tipo de discriminación, cuando dichos dolores o sufrimientos sean infligidos por un funcionario público u otra persona en el ejercicio de funciones públicas, a instigación suya, o con su consentimiento o aquiescencia. No se considerarán torturas los dolores o sufrimientos que sean consecuencia únicamente de sanciones legítimas, o que sean inherentes o incidentales a éstas. 2. El presente artículo se entenderá sin perjuicio de cualquier instrumento internacional o legislación nacional que contenga o pueda contener disposiciones de mayor alcance». Sobre esto decir que desde la STEDH Irlanda c. Reino Unido, de 18/1/1978, el Tribunal suele delimitar lo que son y no son torturas atendiendo a que se produzca un daño o sufrimiento psíquico y/o físico severo (y no tanto al fin o al propósito perseguido). Vid. NowaK, M; Y MCARTHur, E; The United Nations Convention Against Torture. A Commentary, Oxford University Press, New York, 2008, p. 67.

22 Así lo dijo en las SSTEDH Irlanda c. Reino Unido, de 18/1/1978; Soering c. Reino Unido, de 7/7/1989; Kudla c. Polonia, de 26/10/2000; y Van der Ven c. Países Bajos, de 4/2/2003.

23 Por todas, STEDH Mubilanzila Mayeka y Kaniki Mitunga c. Bélgica, de 12/10/2006.

24 Así, por ejemplo, en la STEDH Selmouni c. Francia, de 28/7/1999; en la STEDH Rivas c. Francia, de 1/4/2004; y en la STEDH Jalloh c. Alemania, de 11/7/2006.

25 Por poner un ejemplo, en la STEDH Yankov y otros c. Bulgaria, de 11/12/2004, se dijo que rapar a un recluso la cabeza era un trato degradante prohibido por el artículo $3 \mathrm{CEDH}$. Queda claro que «la persona que está privada de libertad lo está de libertad, no de dignidad». Vid. Gimeno SENDrA, V; (et al); Los derechos fundamentales y su protección jurisdiccional. Edisofer, Madrid, 2017, p. 147.

26 También merece destacarse que el TEDH sólo condena en este tipo de asuntos si los hechos probados demuestran que los malos tratos han tenido lugar «más allá de toda duda razonable». Un caso límite fue STEDH Labita v. Italia, de 6/4/2000, donde entendió que no se cumplía el criterio, (decidido por nueve votos contra ocho, y estos ocho Jueces expresaron opinión parcialmente disidente).

27 Vid. Salado Osuna, A; «Los tratos...», cit. p. 100 y ss. Los últimos casos de los que se ha tenido noticia no hacen sino certificar esta afirmación; así STEDH Khani c. Chipre, de 5/6/2018; STEDH Amerkhnov c. Turquía, de 5/6/2018; STEDH Artur Ivanov c. Rusia, de 5/6/2018; y STEDH Abu Zubaydah c. Lituania, de 31/5/2018. 
efectos físicos y psíquicos en el presunto maltratado; su vulnerabilidad; y/o su sexo y edad, entre otros muchos ${ }^{28}$.

Una cuestión que se antoja fundamental es la carga de la prueba. Es sabido que corresponde con carácter general a la víctima, pero, ante la imposibilidad material de que este tipo de malos tratos se lleguen a probar en Estrasburgo, el TEDH ha invertido la misma, creando una presunción de imputabilidad: el Estado debe aportar explicaciones convincentes y suficientes sobre los hechos acaecidos, dado que es responsable de las personas bajo su tutela. Por ello, si las lesiones que ha sufrido una persona no existían antes de pasar por dependencias policiales, entendidas estas en sentido amplio, existe una fuerte presunción de hecho a favor del denunciante (y en contra de los demandados; es decir, corresponde al Estado enervarla $)^{29}$.

\subsection{La vertiente procesal}

La vertiente procesal del artículo 3 CEDH también constituye una obligación consolidada en el Derecho Internacional de los Derechos Humanos ${ }^{30}$. En el marco de la interpretación realizada por el TEDH su origen se cifra en la última década del siglo $\mathrm{xx}$, desarrollándose ampliamente hasta fechas actuales ${ }^{31}$.

Esta vertiente tiene varias implicaciones, todas ellas de suma importancia ${ }^{32}$. En primer lugar, deriva de la misma para el Estado una obligación positiva, basada en que las autoridades lleven a cabo una investigación cuando se denuncien torturas y/o malos tratos; esa investigación debe ser realizada por los órganos competentes, especialmente por quienes gocen de independencia e imparcialidad (esto es, el poder judicial) ${ }^{33}$. A mayor

28 Vid. Casadevall, J; El Convenio..., cit, p. 217.

29 Así, por todas, STEDH Bouyid c. Bélgica, de 28/9/2015; STEDH Rabmi Sabin c. Turquía, de 5/7/2016; y STEDH Tiziana Pennino c. Italia, de 12/10/2017. El TEDH ha desarrollado ampliamente esa obligación positiva de tutelar correctamente a quienes están bajo su custodia, sea en una prisión, sea en comisarías. Vid. LAVRYSEN, L; Human rights..., cit, p. 105 y ss.

30 Vid. Fernández de Casadevante Romaní, C; «La obligación...», cit, p. 30 y ss.

31 El primer caso donde se reconoce es en la STEDH Assenov c. Bulgaria de 28/10/1998; obtiene impulso en la STEDH Labita c. Italia, de 6/4/2000 y en las SSTEDH Khachiev y Akasieva c. Rusia, de 24/2/2005, y Menesheva c. Rusia, de 9/3/2006; y llega hasta nuestros días, con las SSTEDH Ostrovenecs c. Letonia, de 5/10/2017; Shevtsova c. Rusia, de 3/10/2017; Kuparadze c. Georgia, de 21/9/2017; Zolotorev c. Rusia, de 19/9/2017; y Tiziana Pennino c. Italia, de 12/10/2017; los últimos asuntos hasta la fecha donde el Tribunal decreta su vulneración son la STEDH Al Nasbiri c. Rumania, de 31/5/2018; y la STEDH Khani Kabbara c. Chipre, de 5/6/2018.

32 Vid. GARLICKI, L; «Judgments of the European Court of Human Rights (their structure, impact and authority). En Carmona Cuenca, E; y García Roca, J (eds.); ¿Hacia una globalización de los derechos? El impacto de las sentencias del Tribunal Europeo y de la Corte Interamericana, Editorial Aranzadi, Pamplona, 2017, p. 66 y ss.

33 Voz muy autorizada ya nos hizo ver que la auténtica protección contra estos abusos sólo podía provenir del poder judicial. Vid. Tomás y Valiente, F; «La tortura en España», Obras Completas, Madrid, CEPC, 1997, p. 883 y ss; también es muy recomendable su escrito «Sobre la tortura y otros males menores», recogido en ToMÁs Y Valiente, F; A Orillas del Estado, Madrid, Taurus, 1996, pp. 74-78. Sobre estas cuestiones no puede eludirse la referencia al Tribunal Supremo de Israel, en concreto a su Sentencia de 6 de septiembre de 1999 (HCJ 5100/94 Public Committee against Torture in Israel and Others $v$. The State of Israel 53(4) PD 817, § 38 [1999]. La traducción oficial en inglés puede verse aquí: http://elyonl.court.gov.il/fileseng/94/000/051/a09/9405 1000.a09.htm.). En esta resolución proscribe la tortura y cualesquiera otros malos tratos como métodos legítimos de investigación/interrogación. Vid. Gur-Aye, M; y Jessbeger F; «The protection of human dignity in interrogations: may interrogative torture ever be tolerated? Reflections in light of recent german and israeli experiences», Israel Law Review, vol. 44-n. ${ }^{\circ}$ 1-2 (2011), pp. 292-262. 
abundamiento, si el denunciado es un agente de policía, el artículo 3 CEDH no sólo permite sino que exige dicha investigación. ¿Cómo debe ser la misma? Debe ser oficial, eficaz, independiente, dotada de preferencia frente a otros asuntos y razonablemente conducida, tanto en tiempo — plazos razonables — como en forma — participación de la víctima y/o familiares ${ }^{34}$.

En segundo lugar, la investigación debe estar en condiciones de desentrañar las causas de lo sucedido y de poder identificar y castigar, en su caso, a los responsables. De lo contrario, la prohibición de tortura o de tratos inhumanos/degradantes quedaría vaciada en la práctica. Además, si se ha llegado a juzgar a los responsables en sede interna, el TEDH también ha dejado dicho que ni el proceso penal ni la sentencia deberían beneficiarse de la prescripción, como tampoco de amnistía o indulto posterior en caso de condena ${ }^{35}$.

Lo realmente importante es no sólo abrir diligencias y realizar la investigación, sino conducirla de forma transparente, eficaz, y exhaustiva por sujetos que actúen de forma escrupulosamente independiente; de lo contrario la investigación no cumplirá los cánones convencionales ${ }^{36}$.

\section{EL ARTÍCULO 3 CEDH EN PARTICULAR: EL CASO DE ESPAÑA}

En el presente apartado se va a prestar atención a las condenas del TEDH a España por vulnerar la norma, desde un punto de vista doble. Primero se trazarán sus rasgos básicos y después se analizarán los motivos de fondo que condujeron a las mismas.

\subsection{Fisonomía de las condenas}

Hasta la fecha, España ha sido condenada en once ocasiones por vulnerar el artículo $3 \mathrm{CEDH}$, aunque ha sido demandada algunas más ${ }^{37}$. La primera condena recayó en 2004 en el asunto Martínez Sala ${ }^{38}$, y a partir de ahí se han sucedido en una secuencia de casi una

34 Vid. LaVrysen, L; Human rights..., cit, p. 62.

35 En la STEDH Okkali c. Turquía, de 12/2/2007, se dijo que si existe condena firme sentenciada por un tribunal esta debe «ejecutarse con ejemplaridad», para que tenga «eficacia preventiva y disuasoria» ( $\$ 65$ y $\$ 78)$; en sentido muy parecido, STEDH Tabirova c. Azerbayán, de 3/10/2013; STEDH Tarasov c. Ucrania, de 31/10/2013; STEDH Mocanu y otros c. Rumania, de 17/9/2014; y STEDH Tiziana Pennino c. Italia, de 12/10/2017. En España se ha indultado a miembros de diferentes cuerpos policiales condenados por sentencia judicial firme por la comisión de un delito de torturas y/o contra la integridad física y/o moral. Desde 1996 hasta la fecha son cuarenta y siete indultos, en clara contradicción con las exigencias de Estrasburgo. Vid. https://civio.es/el-indultometro/buscador-de-indultos/. Consultado el 7 de junio de 2018. Muy crítico se muestra con esta práctica Matia Portilla, F.J; «Examen de las...», cit, en prensa.

36 Por todas, STEDH Khani Kabbara c. Chipre, de 5/6/2018.

37 No se observó vulneración del artículo 3 CEDH en las SSTEDH Díaz Ruano c. España, de 26/4/1994; López Ostra c. España, de 9/12/1994; H.E.F. c. España, de 1/10/2011; A.M.B. y otros c. España, de 28/1/2014; Mohamed Raji y otros c. España, de 16/12/2014; ni en López Elorza c. España, de 12/12/2017. Vid. DíAz Crego, M. ${ }^{\text {; } ; ~ « L a ~}$ jurisprudencia...», cit., p. 794.

38 Vid. Queralt Jiménez, A; «Martínez Sala y otros c. España (STEDH de 2 de noviembre de 2004): la vertiente procedimental del derecho a no sufrir torturas ni penas o tratos inhumanos o degradantes». En ALCÁCER Guirao, R; BeladíEz Rojo, M; y SÁnChez Tomás, J.M (coords). Conflicto y diálogo con Europa: las condenas a España del Tribunal Europeo de Derechos Humanos 2013, Civitas, Madrid, 2013, pp. 37-62. 
por año, hasta llegar a la última y quizá más polémica, la dictada en 2018 en el asunto Portu Juanenea y Sarasola Yarzabal c. España ${ }^{39}$.

En todos los casos menos en uno (B.S), estamos ante hechos relacionados con ilícitos de terrorismo, de pertenencia a banda armada, o análogos (kale borroka $)^{40}$. La segunda similitud es que los demandantes se encontraban o bien en dependencias policiales, o estaban siendo trasladados en furgones policiales, o bien en régimen de detención incomunicada ${ }^{41}$.

Además, en todos los casos el fallo de la condena se concreta por el TEDH aplicando la satisfacción equitativa, mecanismo previsto en el artículo $41 \mathrm{CEDH}$. Martínez Sala vuelve a ser, de nuevo, el leading-case ${ }^{42}$. Hay tres casos que merecen consideración aparte. El primero de ellos es Iribarren Pinillos, donde las cantidades decididas fueron inusualmente altas. Se otorgó al demandante 100.000 euros por daños materiales; 30.000 euros por gastos y costas; y 40.000 euros por daño moral ${ }^{43}$. El segundo es el de B.S., donde lo que pide adicionalmente la demandante es la creación de un Protocolo de actuación para futuros casos similares ${ }^{44}$. El tercer caso es Arratibel, donde no se otorga cantidad alguna porque el demandante no la solicita.

39 Los casos son los siguientes: STEDH Martínez Sala y otros c. España, de 2/11/2004; STEDH Iribarren Pinillos c. España, de 8/1/2009; STEDH San Argimiro Isasa c. España, de 28/9/2010; STEDH Beristain Ukar c. España, de 8/3/2011; STEDH Otamendi Egiguren c. España, de 12/12/2012; STEDH B.S c. España, de 24/7/2012; STEDH Ataun Rojo c. España, de 7/10/2014; STEDH Etxebarría Caballero c. España, de 7/10/2014; STEDH Arratibel Garnandia c. España, de 5/5/2015; STEDH Beortegui c. España, de 31/5/2016; y la última hasta la fecha, STEDH Portu Juanenea $y$ Sarasola Yarzabal c. España, de 13/2/2018.

40 En la STEDH B.S c. España, de 24/7/2012, la condena proviene de no haber investigado de forma efectiva y diligente la denuncia de una prostituta nigeriana en Palma de Mallorca en la que alegó haber sido golpeada reiteradamente por agentes del orden durante el arresto y los interrogatorios. Vid. Carmona Cuenca, E; Arenas Ramiro, M; Fernández Vivas, Y; y Piovesan, F; «Los derechos humanos con perspectiva de género». En CarmONa Cuenca, E; y García Roca, J (eds)., ¿ Hacia una globalización de los derechos? El impacto de las sentencias del Tribunal Europeo y de la Corte Interamericana, Pamplona, Aranzadi, 2017, p. 331 y ss.

41 Vid. Ruiloba Alvariño, J; El convenio europeo para la prevención de la tortura y de las penas o tratos inhumanos o degradantes, de 26 de noviembre de 1987: su aplicación en España, Madrid, Dykinson, 2005; «El Comité para la Prevención de la Tortura (CPT): examen de las visitas efectuadas a España». En Fernández de CaSAdevante Romaní, C; (coord.); España y los órganos internacionales de control en materia de derechos humanos, Madrid, Dilex, 2010, pp. 419480; y «Analogías...», cit.

42 Así, solicitada por los demandantes una satisfacción equitativa que repare los daños causados, el TEDH rebaja ostensiblemente la solicitada por daños morales (de 181.305 euros a 8.000 euros), mientras que condena en gastos y costas íntegramente (12.009 euros).

43 Esta última cantidad fue decidida por cuatro votos contra tres, con opinión disidente de estos. Algunos sectores doctrinales consideran que la primera condena a España por vulnerar materialmente el artículo 3 CEDH es esta (así: Nieva-Fenoll, J; «Primera condena a España por infligir tratos degradantes», Agenda Pública, 14 de febrero de 2018); en realidad el TEDH no condena en dicho caso por tal motivo sino porque no se investigó lo suficiente en sede interna qué policía había lanzando el bote de humo que produjo las lesiones. (ver STEDH Iribarren Pinillos, §51). Vid. DíAz Crego, M. a; «La jurisprudencia...», cit, p. 797.

44 El TEDH, recordando «en lo esencial» que sus sentencias son declarativas, considera que son los Estados los que deben decidir los remedios a adoptar, declarando expresamente que no estamos ante una falla estructural del sistema español (dicho con otras palabras: no estamos ante un Caso Piloto). Vid. Garlecki, L; "Judgments...", cit., p. 57 y ss; y ECHR; Factsheet about Pilot Jugments, http://www.echr.coe.int/Pages/home.aspx?p=press/factsheets (consultado el 15 de junio de 2018). En el ámbito que nos ocupa el TEDH ha empleado recientemente dicha herramienta en la STEDH W.D. c. Bélgica, de 6/9/2016, donde condena a Bélgica por vulnerar el artículo 3 CEDH. La situación, como corrobora el CPT en diversos informes, estaba al borde del colapso, con huelgas casi permanentes de funcionarios de prisiones, ausencia de unas condiciones mínimas de atención y salubridad, así como de tratamientos médicos para los necesitados, entre otras. En 2017 recurrió a la Declaración Pública, mecanismo legítimo aunque de uso muy 
Otra similitud tiene que ver con el acatamiento de las resoluciones. Tal y como acredita el órgano encargado de supervisar tal extremo — el Comité de Ministros del Consejo de Europa- España sigue la tendencia general que muestra con el resto del CEDH: un cumplimiento puntual y sin reservas de las sentencias en cuestión, abonando todas y cada una de las cantidades estipuladas ${ }^{45}$.

Finalmente, debemos dedicar algún espacio al asunto Portu Juanenea y Sarasola Yarzabal. En lo que hace a este epígrafe lo cierto y verdad es que las diferencias que plantea son dos. Por un lado, el TEDH entiende que España ha vulnerado tanto la vertiente procesal como la vertiente material de la norma Por otro, la vulneración procesal se observa no tanto por incumplir la obligación de investigar (hubo dos juicios internos, ante al Audiencia Provincial de Guipúzcoa y ante el Tribunal Supremo) sino porque se realizó quebrantando algunas garantías mínimas en la segunda instancia, incardinadas usualmente en el artículo 6.1 $\mathrm{CEDH}^{46}$. Al ser ambas razones de fondo, las dejamos para líneas posteriores.

\subsection{Fisiología de las condenas}

Dejando de lado, pues, tales salvedades, en el resto de asuntos las condenas presentan unos supuestos de hecho y una fundamentación jurídica casi idéntica ${ }^{47}$, acreditando que los órganos judiciales internos no investigaron lo suficiente las denuncias de torturas/ malos tratos realizadas en su día ${ }^{48}$. Dicho con otras palabras, el principal argumento que conforma la ratio decidendi es que la vulneración se produce al no haberse investigado ni

extraordinario, haciendo ver que la situación podía desembocar en tragedia. Vid. SANTAMARÍA Arinas, R; Y Bolaño Piñeiro, M. ${ }^{a}$.C; «Prohibición...», cit, p. 56.

45 Según la Resolution CM/ResDH(2017)281, el Comité ha informado positivamente de los asuntos San Argimiro Isasa y Etxebarría Caballero. Lo mismo puede decirse de la Resolution CM/ResDH(2011)266, que hace lo propio con el asunto Iribarren Pinillos, y de la Resolution CM/ResDH(2011)159, que observa satisfecha la reparación en el asunto Martínez Sala. Los datos se han consultado aquí: https://hudoc.echr.coe.int/eng, el 10 de junio de 2018. Los problemas que plantea en otros ordenes la ejecución de las sentencias del TEDH se estudian, entre otros, por RIPOL Carulla, S; El sistema europeo de protección de los derechos humanos y el Derecho español, Atelier, Barcelona, 2007, p. 73 y ss; Arangüena Fanego, C; y Landa Arroyo, C; «Mecanismos procesales internos para la ejecución de sentencias». En Carmona Cuenca, E; y García Roca, J (eds.); ¿Hacia una globalización de los derechos? El impacto de las sentencias del Tribunal Europeo y de la Corte Interamericana, Pamplona, Aranzadi, 2017, pp. 169-209; y SAAVEDRA Alessandri, P; Cano Palomares, G; y Hernández Ramos, M; «Reparación y supervisión de sentencias», pp. 211-268. En Carmona Cuenca, E; y García Roca, J (eds.); ¿Hacia una globalización de los derechos? El impacto de las sentencias del Tribunal Europeo y de la Corte Interamericana, Pamplona, Aranzadi, 2017.

46 Vid. EsParza Leibar, I; y Etxebarría Guridi, J.F; «Derecho a un proceso equitativo». En Lasagabaster Herrarte, I (dir.), Convenio Europeo de Derechos Humanos: Comentario Sistemático, Civitas, Madrid, 2015 (3. ${ }^{a}$ edición), pp. 264 y ss; Vidal Zapatero, J.M; «El derecho a un proceso público». En García Roca, J; y Santolaya Machetti, P; (coords); La Europa de los Derechos. El Convenio Europeo de Derechos Humanos, CEPC, Madrid, 2014 (3. edición) p. 265 y ss; AlCÁCER Guirao, R; El derecho a una segunda instancia con todas las garantías, Tirant lo blanch, Valencia, 2013; LóPez Guerra, L; «El diálogo...», cit. p. 144 y ss; y Matia Portilla, F.J.; «Examen de las...», cit, en prensa.

47 Estudian los casos en profundidad Rodríguez Boente, S.E; 83 Argumentos que convencen al Tribunal Europeo de Derechos Humanos, Thomson Reuters-Aranzadi, Cizur Menor, 2016, pp. 25 y ss; y Villalibre Fernández, V; «Confluencia del Derecho a la Tutela Judicial Efectiva con el concepto de investigación oficial eficaz en el contexto de la prohibición de la tortura», Foro: Revista de ciencias jurídicas y sociales, vol. 15-n. ${ }^{\circ} 1$, 2012, pp. 29-86.

48 Para estudiar las particularidades del derecho a la tutela judicial efectiva en el sistema del CEDH puede verse Milone, C; El Derecho a la tutela judicial efectiva en la jurisprudencia del Tribunal Europeo de Derechos Humanos, 
suficiente ni eficazmente las mismas, lo cual trae causa de que los tribunales internos sobreseyeron las causas sin practicar ulteriores pruebas que contribuyeran a esclarecer los hechos.

Hay un aspecto dentro de la fundamentación jurídica que merece glosa aparte. Y es que el TEDH utiliza expresamente las recomendaciones que el CPT ha dictado para el caso de España ${ }^{49}$. Esta práctica viene siendo empleada al menos desde los asuntos Ocalan I y Ocalan $I I^{50}$, y se ha mantenido constante a lo largo y ancho de su jurisprudencia hasta la actualidad ${ }^{51}$. Para los casos que nos ocupan, dicha técnica ha sido implementada en todos los asuntos menos en Martínez Sala, (quizá precisamente por eso, por ser un caso anterior a la saga Ocalan). Las recomendaciones que nos viene realizando el CPT no son sino producto del sistema de visitas a diversos centros de detención nacionales desde el año 1990 , y cuya principal crítica es, entre otras y en lo que interesa al objeto del presente trabajo, las condiciones que rodean a las detenciones incomunicadas (y en general, su mera existencia $)^{52}$. De esa manera ha dotado de eficacia jurídica a unos informes que, en su idea original, eran fundamentalmente recomendaciones y observaciones que se le formulan al Estado interesado respecto a su sistema preventivo contra la tortura y demás malos tratos.

Como se decía antes, en el asunto Portu Juanenea y Sarasola Yarzabal subsisten dos grandes diferencias que hacen necesario comentario aparte.

Por un lado, la consabida primera vez que se condena a España por vulnerar la vertiente material del artículo $3 \mathrm{CEDH}$. Así, aplicando la jurisprudencia convencional en la materia, el TEDH se decanta por la lectura que hace del caso de autos la Audiencia Provincial y no por la del Tribunal Supremo. Con sus propias palabras, «no acaba de comprender esa nueva lectura que hace el Tribunal Supremo de los peritos, donde considera

Valencia, Tirant lo blanch, 2015. Sobre el deber de investigar desde el Derecho Internacional puede verse los trabajos de FERnÁndez de CaSAdeVAnte y Romaní, C; «La obligación ...», cit. y «El derecho ...», cit.

49 Por todos, García Roca, J; y Nogueira Alcalá, H; «El impacto de las sentencias europeas e interamericanas: valor de precedente e interpretación vinculante». En CARMONA CuenCA, E; y García Roca, J (eds.); ¿Hacia una globalización de los derechos? El impacto de las sentencias del Tribunal Europeo y de la Corte Interamericana, Pamplona, Aranzadi, 2017, p. 75 y 76.

50 En Ocalan I (STEDH Ocalan c. Turquía, de 12/5/2005), el Tribunal estima que las condiciones de cumplimiento de la pena no superan ese «umbral mínimo de gravedad» necesario para violar el artículo 3 CEDH (\$196). Por el contrario, en Ocalan II (STEDH Ocalan c. Turquía, de 18/3/2014) realiza un exhaustivo desbroce de aquéllas, concluyendo que se vulnera este desde 2005 hasta 2009 ( $\$ 146$ y ss), pero no de 2009 en adelante ( $\$ 148$ y ss). Esta última fue objeto de tres opiniones disidentes. Vid. CHINCHón Álvarez, J; «Turquía y la jurisprudencia del Tribunal Europeo de Derechos Humanos sobre tortura: algunas reflexiones tras los casos Getirem, Kemal Kahraman, Osman Karademir, Osmanoçlu, Balçik y otros, contra Turquía», n. ${ }^{3} 33$, 2009, pp. 591-615; y Allué BuizA, A; «Los derechos fundamentales en Turquía, un claro retroceso», Teoría y Realidad Constitucional, n. ${ }^{\circ}$ 38, 2016, pp. 471485. La deriva del país es sumamente inquietante, tal y como lo explica KABOGLU, I; «Turquía: supresión del régimen parlamentario bajo el estado de emergencia (Observaciones preliminares sobre la modificación constitucional aprobada por el referéndum de 16 de abril de 2017)», Teoría y Realidad Constitucional, n. ${ }^{\circ}$ 40, 2017, pp. 487-505.

51 Por todos, ver STEDH Khani Kabbara c. Chipre, de 5/6/2018, § 156. La primera vez que la Comisión toma en consideración tales informes fue en la DCEDH S.M E T c. Austria, de 10/07/1991; y dos años más tarde volvió a hacerlo en la DCEDH L.J. c. Finlandia, de 28/5/1995. Por su parte, la primera vez que el TEDH lo hace es en la STEDH Amuur c. Francia, de 18/10/1993, lo que repite en la STEDH Aerts c. Bélgica, de 30/07/1998. Vid. CruZ, J; El Comité..., cit, p. 95 y ss.

52 Vid. Morte Gómez, C; «El régimen de detención incomunicada en España: las obligaciones positivas procesales derivadas de artículo 3 del Convenio Europeo de Derechos Humanos». En López Guerra, L (coord; et. al.); El Tribunal Europeo de Derechos Humanos. Una visión desde dentro. En homenaje al Juez Josep Casadevall, Tirant lo blanch, Valencia, 2015, pp. 311 y ss. 
que las lesiones se produjeron como resultado de factores posteriores sobrevenidos e indeterminados. Eso cuando la Audiencia había considerado probado que «todos los peritos estaban de acuerdo en que las fracturas de las costillas se produjeron de forma progresiva a lo largo del día de la detención y que probablemente estuvieron causadas por el movimiento del vehículo y por la postura sentada del detenido durante su traslado a Intxaurrondo» (§80). Y sigue: «el Tribunal no puede sino constatar que el Tribunal Supremo se limitó a rechazar la versión de los demandantes sin determinar el origen de las lesiones establecidas por los informes médicos, en relación con la detención y custodia por los miembros de la guardia civil, o la posible parte de responsabilidad de estos agentes. Incluso suponiendo que pudiera aceptarse la versión del Tribunal Supremo sobre el origen de las lesiones en el momento de la detención, este tribunal no examinó la cuestión de si el recurso a la fuerza física por parte de los agentes de la guardia civil durante esta operación fue estrictamente necesario y proporcional (... ) o si las lesiones más graves sufridas por el primer demandante, después de su detención, según el Tribunal Supremo, fueron responsabilidad de los agentes responsables de su vigilancia y detención, cuando éste estuvo siempre en detención provisional incomunicada, y por tanto, bajo el control de la guardia civil» (§81). Lo cual se añade a que «el Gobierno no ha demostrado las circunstancias exactas de la detención de los demandantes ni establecido que la fuerza utilizada por los oficiales involucrados en esta operación haya sido proporcionada» (§82). En consecuencia, «el Tribunal juzga que está suficientemente establecido que las lesiones descritas en los dictámenes presentados por los demandantes, cuya existencia no niegan ni el Tribunal Supremo ni el Gobierno se produjeron cuando estaban en manos de la guardia civil. Considera que ni las autoridades internas ni el Gobierno han proporcionado argumentos convincentes o creíbles que puedan explicar o justificar en las circunstancias del presente asunto, las lesiones sufridas por los demandantes. Por tanto, el Tribunal estima que la responsabilidad de las lesiones descritas es imputable al Estado acusado» (§83). Quizá lo más sorprendente llega a continuación: cuando todo parecía abocar a una condena por torturas, el TEDH estima, en un escueto párrafo, que «en la medida en que los demandantes no alegaron que las lesiones en cuestión tuvieran efectos secundarios a largo plazo sobre ellos (...) y en ausencia de prueba concluyente relativa a la finalidad de los tratamiento infligidos (...), el Tribunal estima que los malos tratos infligidos a los demandantes no pueden ser calificados como torturas. Siendo así, fueron lo suficientemente graves para ser considerados tratos inhumanos o degradantes» $(\$ 84)^{53}$.

La segunda diferencia es que, aunque también se condena por vulnerar la vertiente procesal, se hace por motivo parcialmente diferente al resto (que no diferente al sistema del CEDH). Aplicando firmes criterios jurisprudenciales precedentes, el TEDH observa que «el Tribunal Supremo no se limitó a efectuar una interpretación diferente de las pruebas documentales, asimismo reevaluó la credibilidad de los testimonios de ambos demandantes, querellantes en el procedimiento interno, así como la de otros testigos (...). Esta nueva valoración de las pruebas de carácter personal, sin una valoración directa por el Tribunal Supremo y en contradicción con las conclusiones del tribunal de instancia, que tuvo la oportunidad de escuchar el testimonio de los demandantes, los acusados

53 La resolución se acompaña de voto particular parcialmente disidente y parcialmente concordante de tres Jueces, quienes consideran que los malos tratos probados son torturas y no tratos inhumanos/degradantes. Sobre la diferenciación entre ambos conceptos, vid. supra. epígrafe 2.1 . 
y de todos los testigos en una audiencia pública, fue determinante para concluir la absolución de los guardias civiles acusados» (§83). Lo cual, también es sabido, conecta con otro de los grandes «vectores de condena» a España en Estrasburgo, toda vez que se incumple con las garantías procesales que establece el artículo 6.1 $\mathrm{CEDH}^{54}$. Con las propias palabras del TEDH: «(...) cuando los tribunales de apelación o de recurso revisan las pruebas de carácter personal como los testimonios de los testigos o de los acusados y llegan a conclusiones opuestas a las establecidas por la jurisdicción a quo, las exigencias de un proceso equitativo hacen indispensable la celebración de una audiencia pública ante el tribunal de apelación o de recurso, para que éste pueda tener un conocimiento directo e inmediato de dichos elementos de prueba (...)» (\$93). Acto seguido, conecta tal extremo con la vertiente procesal más clásica, la anclada en el artículo $3 \mathrm{CEDH}$, toda vez que «Dichas omisiones impidieron que la jurisdicción nacional estableciera los hechos y el conjunto de las circunstancias de una forma tan completa a como podría haberlo hecho, si conforme a la obligación que demanda el artículo 3 del Convenio hubiera sometido el caso ante él a un examen escrupuloso» (\$94).

\section{LA REACCIÓN DE ESPAÑA ANTE LAS CONDENAS}

La reacción de España ante el acervo de jurisprudencia convencional reseñado es notable. Por un lado, se debe aludir a la integración de los criterios de Estrasburgo realizada por el Tribunal Constitucional ${ }^{55}$. Por otro lado, no pueden obviarse algunas reformas legales tendentes tanto a eliminar ciertos resquicios que estaban bajo sospecha como a seguir implementando mecanismos preventivos de cualesquiera malos tratos.

\subsection{La reacción del Juez de la Constitución}

Que la jurisprudencia constitucional es, quizá, el instrumento decisivo a la hora de recepcionar los criterios que provienen de Estrasburgo es cosa poco discutida ${ }^{56}$. Tampoco es objeto de litigio que nuestro Juez Constitucional viene aplicando los criterios del $\mathrm{TEDH}^{57}$, aun con los problemas que esas «interconexiones entre jurisprudencias» suelen

54 España ha sido condenada en once ocasiones por no cumplir con los requisitos del artículo 6.1 CEDH en lo que hace a las garantías que deben rodear a la segunda instancia penal. Y ha sido «absuelta», en asuntos de igual índole, en cuatro ocasiones (entre las cuales está la última dictada hasta la fecha, STEDH Vilches Coronado y otros $c$. España, de 13/3/2018). Sobre el particular véase Esparza LeIbar, I; y EtXEBARría Guridi, J.F; «Derecho...», cit. pp. 264 y ss; Vidal Zapatero, J.M; «El derecho...», cit. p. 265 y ss; Alcácer Guirao, R; El derecho..., cit, p. 31 y ss; y LóPEZ Guerra, L; «El diálogo...», cit. p. 144 y ss.

55 Vid. Matia Portilla, F.J; «Examen de las...», cit, en prensa.

56 Vid. Arzoz Santisteban, X; La concretización y actualización de los derechos fundamentales, CEPC, Madrid, 2014, p. 177 y ss; García Roca, J; «El diálogo entre el Tribunal Europeo de Derechos Humanos y los tribunales constitucionales en la construcción de un orden público europeo»; Teoría y Realidad Constitucional, n. ${ }^{\circ}$ 30, 2012, p. 217 y ss; y SALVAdor MARTíNeZ, M. a ; «Influencias recíprocas entre ordenamientos en el reconocimiento y determinación del contenido de los derechos fundamentales de Europa». En Presno Linera, M.A; y Gutiérrez GutiéRREZ, I (coords); La inclusión de los otros: símbolos y espacios de la multiculturalidad, Comares, Granada, 2012, p. 30 y ss.

57 Nuestra doctrina suele criticar tanto la timidez del legislador a la hora de articular mecanismos generales para ejecutar las resoluciones de Estrasburgo, como el lento ritmo de acogida de estas por la jurisprudencia 
plantear ${ }^{58}$. No cabe duda que el artículo 10.2 CE ha prestado y sigue prestando servicios muy importantes a la hora de interpretar nuestro catálogo de derechos fundamentales ${ }^{59}$.

En lo que hace al objeto específico aquí estudiado debemos distinguir dos momentos bien definidos. El primero lo conforman un grupo de resoluciones dictadas antes del asunto Martínez Sala, donde se maneja un primigenio canon de investigación suficiente ${ }^{60}$. El segundo lo conforman todas aquellas resoluciones post Martínez Sala, donde el TC va integrando en diferentes amparos los criterios de Estrasburgo ${ }^{61}$.

Dentro de este segundo grupo se debe reseñar, a su vez, una doble divisoria. Primero, la recepción que otorga el amparo y, en segundo lugar, la recepción que deniega el $\operatorname{amparo}^{62}$

El primer caso donde el Tribunal Constitucional recepciona los criterios de Estrasburgo es en la STC 224/2007, que abre la saga de otorgamientos de amparo por entender lesionado el artículo $24 \mathrm{CE}$ en relación con el artículo $15 \mathrm{CE}^{63}$. En su FJ 3 acoge expresamente los criterios del Tribunal Europeo de Derechos Humanos y llega a la conclusión de que si el juez nacional deniega «inmotivadamente o irrazonablemente» la demanda, se lesiona el derecho a la tutela judicial efectiva recogido en el artículo 24.1 CE. Es lo que sucede precisamente en este caso, a juicio del TC, por lo que anula la decisión del juez ordinario y ordena la retroacción de las actuaciones al momento de dictar el Auto.

En la siguiente oportunidad que tuvo desarrolló en profundidad las exigencias supranacionales. Así sucede en la STC 34/2008, auténtico leading-case donde se establecen los criterios para determinar si existe o no una investigación oficial eficaz, realizando un minucioso

constitucional. Vid. López Guerra, L; «El Derecho Constitucional en España hoy», en Pérez Tremps, P (comp.); El Derecho Constitucional de comienzos del siglo XXI en la Europa mediterránea Homenaje a los profesores Louis Favoreu, Alessandro Pizzorusso y Francisco Rubio Llorente, CEPC, Madrid, 2017, p. 197 y ss. Un estudio en profundidad sobre la interrelación de ambos puede verse en Queralt JimÉnez, A; La interpretación de los derechos: del Tribunal de Estrasburgo al Tribunal Constitucional, Madrid, CEPC, 2008.

58 Vid. Stone Sweet, A; y Keller, H; «The reception of the ECHR in National Legal Orders», en Keller, H; y Stone Sweet, A; (eds.); A Europe of Rights. The impact of the ECHR on National Legal Systems, New York, Oxford, 2008, p. 3 y ss; para el caso español, GAY MonTalvo, E; «El diálogo entre el Tribunal Constitucional Español con la doctrina de otros Tribunales». En MAC-Gregor Ferrer; y Herrera García, A (coords); Diálogo Jurisprudencial en Derechos Humanos entre Tribunales Constitucionales y Cortes Internacionales, Valencia, Tirant lo blanch, 2013, p. 250 y ss; MARTín-Retortillo BAQUer, L; «La recepción por el Tribunal Constitucional de la Jurisprudencia del Tribunal Europeo de Derechos Humanos», en La Europa de los Derechos Humanos, Madrid, CEPC, 1998, p. 251 y ss; y TenORIo SÁNCHEZ, P; «Influence of the European Convention of Human Rights on the interpretation of the spanish Constitution. A European Perspective». Revista General de Derecho Constitucional, n. ${ }^{\circ}$ 9, 2010, p. 1 y ss.

59 Vid. SAIZ ARNÁIZ, A; La apertura constitucional al derecho internacional y europeo de los derechos humanos: el artículo 10.2 de la Constitución española, Madrid, CGPJ, 1999 y CANDELa Soriano, M., "The reception process in Spain and Italy», en Keller, H; y STONE SweEt, A; (eds.); A Europe of Rights. The impact of the ECHR on National Legal Systems, Oxford, New York, 2008, pp. 404 y ss. Asimismo Arzoz Santisteban, X; La concretización..., cit, pp. 177 y ss; Dítz-Picazo, L.M. ${ }^{\text {; } ; ~ S i s t e m a ~ . . ., ~ c i t, ~ p . ~ 157 ; ~ y ~ C A N o s a ~ U s e r a, ~ R ; ~ E l ~ d e r e c h o ~ . . ., ~ c i t, ~ p . ~} 184$ y ss;

60 Nos referimos a la STC 65/1986, a la STC 2/1987, al ATC 333/1997, a la STC 32/2003, a la STC 7/2004, y en la STC 148/2004. Vid SAIZ ARnÁrz, A; La apertura ..., cit, pp. 261 y 262.

61 Vid. DíAz Crego, M.a.; «La jurisprudencia...», cit, p. 797 y ss.

62 Vid. Rodríguez Boente, S.E; 83 argumentos...cit, p. 28; y Villalibre Fernández, V; «La confluencia...», cit., p. 83 .

63 Regla que lleva a todos los amparos, y que implica un canon reforzado de protección que obliga a apurar los medios para esclarecer los hechos denunciados. Vid. González Alonso, A; La tutela jurisdiccional de los derechos del artículo 24.1 de la Constitución Española, Tesis Doctoral, UAM, Madrid, 2012, p. 162 y ss (consultada aquí: https:// repositorio.uam.es/handle/10486/9207, el 10 de junio de 2018). 
desbroce de las circunstancias particulares que debe tener en cuenta el juez instructor cuando se encuentre investigando la denuncia de torturas y/o de tratos inhumanos o degradantes. Para saber si estamos ante una investigación oficial eficaz (FJ 7), establece un prerrequisito — que exista sospecha razonable de haber sufrido ese maltrato y que la misma resulte disipable, y un triple criterio. El primero es la apariencia de verosimilitud de las sevicias denunciadas. El segundo es que, si existen lesiones después de entrar en comisaría y no antes, se presume que las mismas son atribuibles a los encargados de la custodia de la persona lesionada. El tercero es que se considera «particularmente idóneo» el testimonio judicial del denunciante, así como toda declaración previa de médicos, y/o policías.

A partir de ahí, el Tribunal Constitucional aplica tales exigencias a los amparos que se le presentan. En la STC 52/2008 otorga el amparo, aunque no sin cierta discrepancia ${ }^{64}$. La STC 69/2008 otorga el amparo a un etarra: las sospechas eran razonables, debió seguir investigándose, no se hizo, ergo se vulneró el art. 24 CE en relación con el artículo 15 CE. Igualmente sucede en la STC 107/2008, donde «existieron medios de investigación disponibles» que no se implementaron. En la STC 63/2010 vuelve a aplicar la doctrina sentada en la STC 34/2008, otorgando el amparo porque el juez no investigó lo suficiente. Además, el TC dejó dicho en esta que ni el efectuar la denuncia dos meses después de producirse las presuntas torturas, ni el hecho de no mencionar las mismas cuando prestó declaración dotan de menor credibilidad a la misma [FJ 3 a) $]^{65}$. En la STC 131/2012 otorga el amparo, en este caso con un argumento adicional de cierta novedad. Y es que el canon de investigación suficiente se refiere «tanto a la inexistencia de sospechas razonables como a la utilidad de continuar con la instrucción» (FJ 2). En la jurisprudencia más reciente no parece que haya habido grandes cambios, tal y como amerita el otorgamiento del amparo en las SSTC 153/2013, 130/2016, 144/2016 y 39/2017 .

Dentro de la recepción que deniega amparo destaca la STC 63/2008, por ser la primera en la que no se concede. Entiende el Tribunal Constitucional suficiente la investigación realizada y, por ende, no observa vulneración del derecho a la tutela judicial

64 El Magistrado Rodríguez-Zapata disiente de la mayoría, en tanto considera que el canon de Estrasburgo se cumplió por parte de la jurisdicción ordinaria y, en consecuencia, no procedía la concesión del amparo. Con sus propias palabras: «(...) Si el detenido se niega a colaborar en la investigación del hecho que denuncia, si en el informe hospitalario no se reflejan indicios de maltrato, si mientras estaba detenido en dependencias policiales fue visitado en cuatro ocasiones por un Médico forense y no adujo maltrato alguno — ni el forense lo apreció por sísi el Abogado de oficio que le asistía tampoco advirtió ninguna irregularidad al respecto no creo que pueda afirmarse, como hace la Sentencia, que concurren sospechas razonables acerca de la posible comisión de los hechos denunciados. Para llegar a tal conclusión la Sentencia valora el material probatorio, pese a calificarlo como insuficiente, con una desenvoltura más propia de un órgano de la jurisdicción penal que de un Tribunal Constitucional (...)». Apartado 3 del Voto Particular.

65 A juicio de la doctrina, esta resolución es uno de los ejemplos más acabados de diálogo judicial. Por todos, García Roca, J; «El diálogo...», cit, p. 217.

66 Resulta interesante la aclaración que realiza el Tribunal Constitucional, al entender que «(...) de la jurisprudencia del Tribunal Europeo de Derechos Humanos no se infiere la necesidad de llevar a cabo un elenco cerrado y taxativo de diligencias de investigación en los casos de denuncia de torturas o malos tratos de personas bajo custodia policial, pero sí se desprende que, incluso en aquellos casos en que los informes médicos no revelan indicios claros de la comisión de un delito de tortura, han de practicarse otros medios de prueba adicionales, agotando cuantas posibilidades de indagación resulten útiles para aclarar los hechos denunciados. El art. 3 del Convenio europeo para la protección de los derechos humanos y de las libertades fundamentales tiene una doble vertiente sustantiva y procesal y puede producirse una violación de esta última cuando la imposibilidad de determinar, más allá de toda duda razonable, que el denunciante fue sometido a malos tratos se desprende en gran medida de la ausencia de una investigación oficial exhaustiva y efectiva tras la denuncia presentada (...)» (FJ 2, con cita expresa de la STC 130/2016). 
efectiva. La denuncia se sobreseyó por falta de credibilidad del denunciante, materializada en diversas razones (FJ 4). Primero, formular la demanda casi diez meses de los supuestos hechos que la provocaron; segundo, durante el examen médico negó haber sufrido agresión alguna; tercero, no concretó ni especificó nada respecto a las amenazas verbales; y cuarto, las pruebas del examen forense no se compadecían con los episodios de violencia que alegó originariamente.

Lo mismo sucede en la STC 123/2008, donde se deniega amparo porque no basta con formular «una mera denuncia vacía de argumentación». Constata el Juez de la Constitución que se practicaron todas las diligencias que despejaron las dudas del juez ordinario (las cuales incluían, entre otras, informes médicos previos que acreditaron la inexistencia de torturas). Con sus propias palabras: "Por el contrario, si - como sucede en el presente caso- no concurre el presupuesto del deber de profundizar en la investigación, esto es, la existencia de sospechas razonables susceptibles de ser despejadas, no resulta constitucionalmente exigible el desarrollo de mayor actividad instructora y el derecho a la tutela judicial efectiva, en relación con el art. $15 \mathrm{CE}$, no resulta vulnerado por la decisión de clausurar la investigación» [FJ 3d)]. Uno de los casos más señalados es el de la STC 128/2012. Se deniega el amparo de un etarra porque la investigación fue suficiente. El TC llega a dicha conclusión empleando los cánones de constitucionalidad y convencionalidad. En el FJ 2 insiste en que las sospechas «deben ser razonables y los medios de investigación razonables y eficaces». Y en el FJ 4 añade que la investigación suficiente no exige realizar todas y cada una de las diligencias propuestas, «lo cual, además, podría prorrogar indebidamente la misma (...)». En la STC 12/2013 se deniega el amparo a un etarra porque, a juicio del Tribunal Constitucional, ni hubo sospechas razonables, ni de los informes médicos y de las declaraciones del recurrente se desprendieron indicios de maltrato físico/psíquico, ni se aportó indicio alguno que acredite la veracidad de esos tratos ${ }^{67}$.

\subsection{La reacción del legislador}

La reacción del legislador podría decirse doble. Por un lado, debe reseñarse la implementación del Mecanismo Nacional de Prevención de la Tortura ${ }^{68}$. Al firmar España el OPCAT una de las obligaciones que rubricó fue crear un herramienta nacional que garantizase, a través de un sistema de visitas a centros de detención y/o penitenciarios, la prevención de la tortura y de cualesquiera malos tratos ${ }^{69}$. De esa manera, y mediante la Ley Orgánica $1 / 2009$, de 3 de noviembre, se ejecuta el mandato, atribuyendo dicha función al Defensor del Pueblo ${ }^{70}$. La misma norma creó el Consejo Asesor, órgano de cooperación

67 La sentencia fue debatida y la discrepancia de dos Magistrados se llevó al correspondiente voto particular. Un análisis crítico de la misma puede leerse en SÁNCHEZ ToMÁs, J.M; «El deber judicial de investigación eficaz de las denuncias creíbles por tortura: comentario a la STC 12/2013, de 28 de enero", La Ley Penal, n. ${ }^{\circ} 102$, 2013 , pp. 7 y ss.

68 Vid. Mariño Menéndez, F.M; y Cebada Romero, A. (Dirs. ): La creación del mecanismo español de prevención de la tortura, Iustel, Madrid, 2009.

$69 \mathrm{El}$ sistema ONU se encuentra ampliamente inspirado en el sistema Consejo de Europa, aunque gozan de algunas diferencias que aquí sólo podemos apuntar. Vid. Ruiloba Alvarĩ̃o, J; «Analogías...», cit, p. 265 y ss.

70 Un estudio de esa defensa procesal puede verse en Torres Muro, I; «Los recursos del Defensor del Pueblo ante el Tribunal Constitucional: una revisión», Teoría y Realidad Constitucional, n. ${ }^{\circ}$ 26, 2010, pp. 95-126. 
técnica y jurídica del MNPT y presidido por el Adjunto en quien el Defensor delegue ${ }^{71}$. La decisión de no dotarlo de estructura independiente y formalmente separada de nuestro Ombudsman ha suscitado algunas críticas, aunque no parece que haya sido un obstáculo real para que el MNPT lleve a cabo sus tareas con toda garantía y libertad, tal y como lo acredita la doctrina y la propia Institución ${ }^{72}$.

Por otro lado, se han reformado algunas leyes para intentar dar acomodo a los criterios de Estrasburgo (en general, del Consejo de Europa y de diversos organismos internacionales de protección) destacando especialmente los cambios operados en la Ley de Enjuiciamiento Criminal de $2015^{73}$.

Una de las novedades reseñables de la misma es que el detenido tiene derecho a entrevistarse personal, privada y previamente con su letrado antes del interrogatorio policial, lo cual no sólo acrece a una mejor defensa procesal sino también a crear un cierto cordón de seguridad material ${ }^{4}$.

Otro cambio destacable es el nuevo régimen de la detención incomunicada. Por un lado, porque las causas para dictaminarla se limitan a dos, y deben observarse siempre velando por la salvaguarda del principio de proporcionalidad. Además, el plazo máximo que puede pasar una persona en régimen incomunicado es de cinco días, prorrogables por otros cinco si se trata de delitos de terrorismo o cometidos por organización criminal. Se elimina, pues, la segunda incomunicación por tres días ${ }^{75}$. Mientras dure el régimen, el juez «controlará efectivamente» las condiciones de desarrollo. Y en todo caso debe

71 Vid. Ruiz LegazPI, A; «La prevención de la tortura: ¿una novedad en el frente del Defensor del Pueblo?». En Roca Escobar, G (ed); La protección de los derechos humanos por las defensorías del pueblo, Dykinson, Madrid, 2013, pp. 1105-1111.

72 Existen varios ejemplos comparados de lo mismo. Por ejemplo, México, Costa Rica, República Checa, Dinamarca y Polonia. En el otro extremo está Francia, que decidió crear una institución nueva. Vid. SÁNCHEZ SAUDINós, J.M; «Introducción. La organización y competencias de las Defensorías del Pueblo: panorama general». En Roca Escobar, G (ed); La protección de los derechos humanos por las defensorías del pueblo, Dykinson, Madrid, 2013, pp. 961-980. Por su parte, el informe Anual 2016 del MNPT puede verse aquí: https://www.defensordelpueblo.es/ informe-anual/informe-anual-2016/. Consultado el 30 de mayo de 2018.

73 Recogiendo el guante que la doctrina había lanzado hace tiempo. Vid. Díaz Crego, M.a; «La jurisprudencia...», cit. p. 796 y ss. Un estudio sistemático de la reforma puede verse en MARCHENA GómEZ, M; y GonZÁlez-Cuéllar Serrano, n; La reforma de la Ley de Enjuiciamiento Criminal en 2015, Ediciones Jurídicas Castillo de Luna, Madrid, 2015. Una de las medidas de salvaguarda apoyada por la doctrina y que podría implementarse en futuras reformas, es la instalación de videocámaras en comisarías y centros de detención, «incluso el anuncio de la mera posibilidad de que hayan sido instaladas»

74 Artículo 520.6. d) LeCrim; «La asistencia del abogado consistirá en (...): Entrevistarse reservadamente con el detenido, incluso antes de que se le reciba declaración por la policía, el fiscal o la autoridad judicial (...)». La crítica desde instancias internacionales sobre este aspecto era reiterada. Por todos, vid. Nowak, M; y McArthur, E; The United Nations..., cit., p. 58.

75 Artículo 509 LeCrim: «1. El juez de instrucción o tribunal podrá acordar excepcionalmente, mediante resolución motivada, la detención o prisión incomunicadas cuando concurra alguna de las siguientes circunstancias: a) necesidad urgente de evitar graves consecuencias que puedan poner en peligro la vida, la libertad o la integridad física de una persona, o b) necesidad urgente de una actuación inmediata de los jueces de instrucción para evitar comprometer de modo grave el proceso penal. 2. La incomunicación durará el tiempo estrictamente necesario para practicar con urgencia diligencias tendentes a evitar los peligros a que se refiere el apartado anterior. La incomunicación no podrá extenderse más allá de cinco días. En los casos en que la prisión se acuerde en causa por alguno de los delitos a que se refiere el artículo 384 bis u otros delitos cometidos concertadamente y de forma organizada por dos o más personas, la incomunicación podrá prorrogarse por otro plazo no superior a cinco días. 3 . El auto en el que sea acordada la incomunicación o, en su caso, su prórroga deberá expresar los motivos por los que haya sido adoptada la medida. 4. En ningún caso podrán ser objeto de detención incomunicada los menores de dieciséis años». 
motivar cada una de las limitaciones de derechos, si observa que proceden, a lo largo de la incomunicación. Por último, aunque no menos importante, el detenido incomunicado deberá ser sometido, al menos, a dos reconocimientos médicos cada 24 horas, según criterio facultativo ${ }^{76}$.

\section{A MODO DE CONCLUSIÓN}

De las líneas anteriores se deduce que España ha sido once veces condenada por vulnerar la vertiente procesal y una por vulnerar la vertiente sustantiva del artículo $3 \mathrm{CEDH}$. Mientras que las primeras se han dictado dado que España ha incumplido la obligación positiva de investigar oficial y eficazmente las denuncias de tortura y/o tratos inhumanos y degradantes, la segunda se ha dictado porque el TEDH considera probado, en un caso, que ciertas acciones de determinados agentes de la ley constituyeron tratos inhumanos/ degradantes. De esas mismas líneas se infiere, además, la importancia de los esfuerzos conjuntos del TEDH y del CPT, ambos órganos de protección de los valores recogidos en el artículo $3 \mathrm{CEDH}$. La secuencia se observa de forma idéntica en casi todos los casos: si el TEDH observa que el CPT ha reiterado aspectos negativos en sus Informes y el Estado no ha adoptado cambios, asume sus criterios en la ratio decidendi y condena (no sólo por eso, claro está, pero sí opera como argumento-fuerza).

Con todo, el balance que puede hacerse es positivo, en líneas generales, dado que España cumple con las exigencias de Estrasburgo. No sólo lo hace con lo que exige la condena en cada caso particular, sino que se están dando pasos institucionales para ir algo más allá. En ese sentido, hay que destacar la labor del Tribunal Constitucional, con una reacción integradora y sostenida en el tiempo, donde acoge los criterios de Estrasburgo en los casos que se le han ido presentando en amparo con un resultado claramente favorable (once otorgamientos de amparo y cuatro denegaciones). Además, destaca la reacción del legislador, donde se han adoptado tanto mecanismos internos para prevenir las conductas que atentan contra la norma (MNPT), como modificaciones puntuales de la legislación procesal penal en aspectos especialmente sensibles a estos efectos (con mención especial para el recorte en el tiempo máximo que se puede detener incomunicadamente a una persona).

En suma, habrá que estar al desarrollo de estas reformas, y de las que puedan venir, para conocer cómo van encajando las piezas. La materia es lo suficientemente sensible como para huir de prisas y frivolidades; pero también es lo suficientemente importante como para no eludir la realidad que muestra.

76 Artículo 527 LeCrim: «1. En los supuestos del artículo 509, el detenido o preso podrá ser privado de los siguientes derechos si así lo justifican las circunstancias del caso: a) Designar un abogado de su confianza. b) Comunicarse con todas o alguna de las personas con las que tenga derecho a hacerlo, salvo con la autoridad judicial, el Ministerio Fiscal y el Médico Forense. c) Entrevistarse reservadamente con su abogado. d) Acceder él o su abogado a las actuaciones, salvo a los elementos esenciales para poder impugnar la legalidad de la detención. 2. La incomunicación o restricción de otro derecho del apartado anterior será acordada por auto. Cuando la restricción de derechos sea solicitada por la Policía Judicial o por el Ministerio Fiscal se entenderán acordadas las medidas previstas por el apartado 1 que hayan sido instadas por un plazo máximo de veinticuatro horas, dentro del cual el juez habrá de pronunciarse sobre la solicitud, así como sobre la pertinencia de acordar el secreto de las actuaciones. La incomunicación y la aplicación al detenido o preso de alguna de las excepciones referidas en el apartado anterior será acordada por auto debiéndose motivar las razones que justifican la adopción de cada una de las excepciones al régimen general de conformidad con lo dispuesto en el artículo 509». 
TITLE: Spain and article 3 of the European Convention on Human Rights: An Evaluation

Abstract: In the text we study article 3 of the European Convention on Human Rights within the Spanish constitutional framework. Firstly, we set the main core of the right, both the substantive and procedural aspects. Secondly, we take a look to the implementation in Spain, in order to find how, why, and when the interpretation given by the Strasbourg Case-Law has been implemented by national authorities. Thirdly, to that extent, we study the national answers, paying attention to the Constitutional Case-Law and to some legal reforms. Lastly, we give a bunch of provisional conclusions.

RESUMEN: En el texto se realiza un balance de la aplicación del artículo 3 del Convenio Europeo de Derechos Humanos al Reino de España. A tal fin se estudia, en primer lugar, las principales vertientes del mismo, tanto material como procesal. En segundo lugar, se analizan las condenas impuestas en Estrasburgo a nuestro país por vulnerar el precepto. En tercer lugar, se aporta una examen de la reacción española ante las condenas, que pasa tanto por la recepción de los criterios de Estrasburgo por nuestro Tribunal Constitucional, como por la implementación de algunas reformas legislativas recientes. Se finaliza con unas conclusiones, en todo caso provisionales.

KEY WORDS: torture, ill-treatment, Spain, European Convention on Human Rights, European Court of Human Rights

Palabras clave: tortura, malos tratos, España, Convenio Europeo de Derechos Humanos, Tribunal Europeo de Derechos Humanos

FECHA DE RECEPCIÓN: 12.06.2018

FECHA DE ACEPTACIÓN: 13.09.2018 